\title{
Multicriteria Evaluation for Port Competitiveness of Eight East Asian Container Ports
}

\author{
Junn-Yuan Teng \\ Associate Professor, Dept. of Industrial Management, Huafan University. Shihdin, Taipei, Taiwan 223.
}

Wen-Chih Huang

Associate Professor, Dept. of Harbor and River Engineering, National Taiwan Ocean University. Keelung, Taiwan 202., huangwc@mail.ntou.edu.tw

Miin-Jye Huang

Candidate, Ph.D., Dept. of Harbor and River Engineering, National Taiwan Ocean University. Keelung, Taiwan 202.

Follow this and additional works at: https://jmstt.ntou.edu.tw/journal

Part of the Business Commons

\section{Recommended Citation}

Teng, Junn-Yuan; Huang, Wen-Chih; and Huang, Miin-Jye (2004) "Multicriteria Evaluation for Port Competitiveness of Eight East Asian Container Ports," Journal of Marine Science and Technology: Vol. 12: Iss. 4, Article 4.

DOI: $10.51400 / 2709-6998.2245$

Available at: https://jmstt.ntou.edu.tw/journal/vol12/iss4/4

This Research Article is brought to you for free and open access by Journal of Marine Science and Technology. It has been accepted for inclusion in Journal of Marine Science and Technology by an authorized editor of Journal of Marine Science and Technology. 


\section{Multicriteria Evaluation for Port Competitiveness of Eight East Asian Container Ports}

\section{Acknowledgements}

The author would like to thank National Science Council of Taiwan, R.O.C. for its support of the research NSC 89-2611-E-019-032. The content of this paper is part of the results from that study. 


\title{
MULTICRITERIA EVALUATION FOR PORT COMPETITIVENESS OF EIGHT EAST ASIAN CONTAINER PORTS
}

\author{
Junn-Yuan Teng*, Wen-Chih Huang**, and Miin-Jye Huang***
}

Key words: port competitiveness, evaluation approach, multicriteria decision making (MCDM), grey relational analysis (GRA).

\section{ABSTRACT}

A great deal of literature applies efficiency measurement methods to investigate port's competitive advantages. Nevertheless, the competitive characteristics of a port are deeply influenced by port policies of government, the operating strategies of the port, operating facilities, and the loading and unloading efficiencies, etc. Therefore, the measurement of a port's overall competitiveness requires considering all internal and external factors. This paper is to clarify the characteristics of a port's competitiveness using GRA model by taking eight East Asian container ports for identification. The ranking orders evaluated by the GRA are as follows: Singapore, Hong Kong, Kaohsiung, Kobe, Taichung, Keelung, Pusan, and Shanghai. The findings represent the most significant criteria including 13 items. Evaluation of port competitiveness shows the effectiveness type of criterion as the principle and the efficiency type of criterion as a minor.

\section{INTRODUCTION}

Port generally can be defined as interface linking marine and inland transportation. Nowadays, a port acts as a base for logistics, production, information, financial, living, international trade function and a base for economic development of hinterland [9]. Nearly ninety percent of global trade is handled through ports. Therefore, a port plays an important role in contributing to the national economy. Moreover, a port's development is related to regional industries, port facilities, government's port policies, and so on. International port competition is deeply affected by a country's po-

Paper Submitted 01/03/04, Accepted 09/06/04. Author for Correspondence: Wen-Chih Huang. E-mail: huangwc@mail.ntou.edu.tw.

*Associate Professor, Dept. of Industrial Management, Huafan University. Shihdin, Taipei, Taiwan 223.

**Associate Professor, Dept. of Harbor and River Engineering, National Taiwan Ocean University. Keelung, Taiwan 202.

***Candidate, Ph.D., Dept. of Harbor and River Engineering, National Taiwan Ocean University. Keelung, Taiwan 202. litical and economical framework. Port competition is of a complex nature [33]. Nevertheless, a lot of literature applies efficiency measurement methods to investigate port competitiveness. This paper is aiming to investigate the characteristics of port competitiveness evaluation.

There is some literature that investigates competitiveness using Data Envelop Analysis (DEA), relative inefficiency method, productivity, production efficiency, etc. Some researches apply multicriteria decision making methods to the evaluation. But, port competition possesses a complex nature. Port functions as a center for logistics, production, information, financial, living, and international trade contributing to the economic development of its hinterland.

This research chooses evaluation methods that consider multiple criteria to explore the characteristics for the evaluation approaches and criteria that determine a port's competitiveness. The limitation of this research are that performance data are not easy to obtain, port authorities do not release transshipment statistics, and certain criteria cannot be collected simultaneously from all ports under evaluation. To cope with insufficient data and uncertainty problem, this study uses Grey Relation Analysis (GRA) in evaluation. Eight competitive container ports in East Asia are selected for an empirical study. They are the ports of Keelung, Taichung, and Kaohsiung in Taiwan, Kobe in Japan, Hong Kong and Shanghai in China, Pusan in Korea, and the port of Singapore.

The criterion data of this study is obtained from two sources, namely statistics and questionnaire survey. The ranking orders are evaluated by the GRA. The most significant criteria include 13 items, which shares near eighty percent of the original. The finding would contribute to the increase effectiveness for this field of research.

The rest of this paper is organized as follows: Section 2 reviews previous researches on port and competitive evaluation. In section 3 a competitiveness evaluation model for embarking upon a follow-up study is put forward. Section 4 evaluates the competitiveness of East Asian container ports using the GRA model. 
Section 5 discusses criteria screening and prospect analysis. And finally Section 6 draws the conclusions and makes the closing remarks.

\section{RESEARCHES ON COMPETITIVENESS EVALUATION}

This section reviews some of the researches related to industrial and port competitiveness. Prescott and Grant [26] is the first article to review competitiveness analysis by comparing the characteristics of 21 evaluation methods [16]. Oral [22] investigates competitiveness methods and induces two types of approaches, including descriptive and analytical approaches. Oral is a pioneer who adopts model-based approaches to embark on competitiveness analysis. Chou et al. [4] uses SWOT to describe competitiveness of four Asian container ports. This belongs to a descriptive approach.

Analytical methods for competitiveness evaluation include the following categories. Jayanthi et al. [16] uses the DEA to evaluate the competitiveness of 20 food factories. Oral [20] applies linear programming to establish a relative inefficiency analysis model. Parkan [23] follows DEA and proposes operational competitiveness ratings analysis (OCRA) model. Parkan and $\mathrm{Wu}$ [24] and Jayanthi et al. [16] adopt the OCRA to measure competitiveness of manufacturing industries. Oral and Dominique [20], Jayanthi et al. [16], Roll and Rachish [28] and Oral et al. [21] use productivity to evaluate industrial efficiency. Tongzon [31] adopts the DEA and Talley uses economic function to measure a port's performance. Tongzon [32] draws up function for overall port performance and efficiency. Other researches investigate the productivity of ports, such as Chang [2], Dowd and Leschine [6], Robinson [27], Sachish [29]. The game theory is adopted by Karnani [18] to analyze the market share in an oligopoly. Dutta and King [7] apply the game theory to establish a competition scenario model to evaluate competitive strategies. Kuroda and Yang [19] and Yang [34] adopt the Stackerlberg equilibrium to establish competition models for a port's carrying volume, and also to investigate the operational strategies of container bases.

Chen [3] researches port competitive advantages by using seven criteria under those categories, port services, container terminal services, and economies and location. Huang et al. [10,11] apply the AHP/GRA to evaluate a container port's competitiveness. Huang et al. $[13,14]$ use a multicriteria grade classification model and AHP plus SWOT (strengths, weaknesses, opportunities, and threads) respectively to assess a port's competitiveness. These researches employ 31 evaluation criteria. Kaohsiung Port Authority [17] researches the competitiveness of its port via core competency by using 60 core resources to measure port competitiveness. Yeo and Song [35] apply AHP to evaluate competitiveness among ten ports in China and Korea using cargo volume, port facility, port location, and service level as criteria. They belong to the multicriteria decision making (MCDM) methods. Institute of Transportation [15] uses 28 criteria to evaluate ten Asian container ports. Those researches consider port as the public sector, for it is of more public interest than it is of private benefit.

Furthermore, the study of Brown and Svenson [1] presents evaluation factors for R \& D performance evaluation. They suggest that evaluation of $R \& D$ productivity has to measure books written, projects completed, awards won, and patents received, but also cost reduction, sale improvement and capital avoidance. The research result implies that evaluation criteria including "efficiency" and "effectiveness" two parts. The evaluation framework of Brown and Svenson [1] is applied in the port performance evaluation, if the loading/unloading moves per ship, unit machine or unit area of loading/unloading efficiency is very high; it doesn't mean that the port acquires a higher overall effectiveness. In other words, efficiency does not automatically imply effectiveness. Please see the evaluation framework in Fig. 1. Based on the studies [1,25], superior port performances, including both "efficiency" and "effectiveness" would produce better port competitiveness.

Huang et al. [12] separates the criteria for port system into two types, efficiency and effectiveness. Effectiveness criteria include degree of congestion, average ship waiting time, waiting time factor, average ship time in harbor, total cost in harbor and so on. Efficiency criteria for port involve input/output operation performance of ships, wharves, and the container freight station subsystems.

Among the above-mentioned evaluation categories, DEA, relative inefficiency, OCRA, and productivity are primarily measuring the entity's operational efficiency. Non-parametric models, such as DEA, OCRA, and the relative inefficiency, need more alternative quantity than the evaluation criteria. Game theories adopt quantitative variables in their decision-making models. And game theories focus on finding some competitive strategies' numerical data from micro viewpoints. Those methods are not pertinent for the eight-port and tens of criteria case.

Several studies [10,11,13,14, 15, 35] use AHP or other multicriteria relative models in competitiveness evaluation, but failed to explore the features of assessment criteria. MCDM methods can take variant factors, qualitative and quantitative, efficient and effective types of criteria of container ports into consideration. This paper aims to follow those studies by using GRA to evaluate a port's competitiveness and explores the fea- 
tures of assessment methods as well as criteria.

Based on the relative researches $[9,25]$, this paper defines port competitiveness as the performances of that port to create regional or nationwide value-added goods and/or services, by producing an industrial clustered effect. These values include the external and the internal values or surplus of the port. Therefore, apart from financial benefit or operational efficiency, ports also pursue non-economical values. Competitiveness is not merely equivalent to productivity. Productivity does not equal competitiveness, nor does it equal labor productivity. Competitiveness includes various economical and non-economical factors in this study.

In the meantime, this study follows Fielding et al. [8] and Talley [30] separate evaluation criteria into "effectiveness type of criterion" and "efficiency type of criterion" in port competitiveness evaluation. Efficiency type of criterion contains port's inputs, output and efficiency, such as labor, operational efficiency, loading \& unloading ratio, terminal movement capability ratio, and other efficiency factors. Effectiveness type of criterion implies the degree to which the whole port system achieves its goal and contains port's outcomes such as operation cost, inbound/outbound cargo, transshipment ratio, and external factors, as custom service, transportation, political, social, economic, and financial environments.

This paper is aiming to use GRA in the competitiveness evaluation for container ports under the conditions of insufficient data and uncertainty. The evaluation model is developed in the following section.

\section{METHODOLOGY}

The GRA is defined as follows [5, 11]:
Definition 1. $X$ is grey relational factor space.

Let $X$ be a grey relational factor space,

$X=\left\{x_{i} \mid x_{i} \in I=\{0,1,2, \ldots, m\}, m \geq 2\right.$,

$x_{i}=\left(x_{i}(1), x_{i}(2), \ldots, x_{i}(n)\right)$,

$\left.x_{i}(k) \in x_{i}, k \in K=\{1,2, \ldots, n\}, n \geq 3\right\}$

Let $\gamma\left(x_{0}(k), x_{i}(k)\right)$ and $\gamma\left(x_{0}, x_{i}\right)$ be positive real numbers, and $\gamma\left(x_{0}, x_{i}\right)$ is the average value of $\gamma\left(x_{0}(k)\right.$, $\left.x_{i}(k)\right)$. If there is a function $\gamma\left(x_{0}(\mathrm{k}), x_{i}(k)\right)$ in the grey relational space satisfying four axioms: norm interval, symmetric duality, wholeness, and approachability, then we call $\gamma\left(x_{0}(k), x_{i}(k)\right)$ a grey relational coefficient of $x_{i}$, comparative series, compared to $x_{0}$, reference series. $\gamma\left(x_{0}, x_{i}\right)$ is a grey relational grade of $x_{i}$ compared to $x_{0}$.

One factor space possesses the following characteristics: existence of key factors, countable factors, expandability of factors, and independence of factors. If an original series satisfies the feature of nonunit, the same scaling, and polarization, then this series is called comparable. Data with various units are transferred to non-unit type by normalization process. Same scaling means that values of $x_{i}(k)$ in row or column $x_{i}$ are the same order, power of ten, or the order difference doesn't exceed two. Polarization means factors in one row or column are describing the same direction.

Definition 2. Space that satisfies features of factor space and comparison is called grey relational space, shown as $(X, \Gamma)$. Where $X$ is grey relational factor space, $\gamma$ is grey relation reflecting from $x_{0}, x_{i}$ to $\gamma\left(x_{0}, x_{i}\right)$, and $\Gamma$ is map set of $\gamma$.

Definition 3. In grey relational factor space $X$ and grey relational space $(X, \Gamma)$, if there is $\gamma\left(x_{0}, x_{j}\right), \gamma\left(x_{0}, x_{p}\right), \ldots$, $\gamma\left(x_{0}, x_{q}\right)$ satisfying $\gamma\left(x_{0}, x_{j}\right)>\gamma\left(x_{0}, x_{p}\right)>\ldots>\gamma\left(x_{0}, x_{q}\right)$, then $x_{j} \gamma x_{p} \gamma \ldots \gamma x_{q}$. The above-mentioned order is called the grey relational order. Noted as $(j, p, \ldots, q: \gamma)$

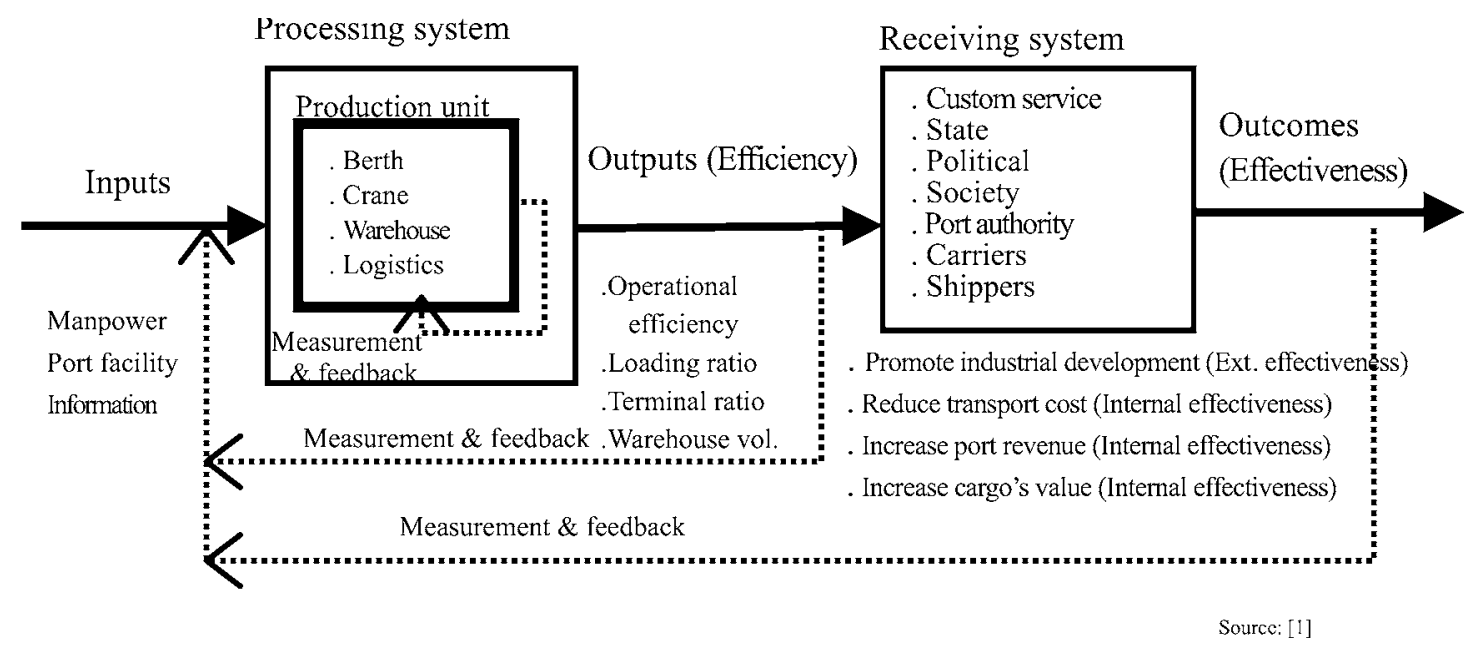

Fig. 1. Port evaluation framework. 
The four axioms are described as follows:

(1) Norm interval

$0<\gamma\left(x_{0}, x_{i}\right) \leq 1, \gamma\left(x_{0}, x_{i}\right)=1$, iff $x_{i}=x_{0} \gamma\left(x_{0}, x_{i}\right)=0$,

$x_{i}, x_{0} \in \varphi$

where $\varphi$ is an empty set.

(2) Symmetric duality $\gamma(x, y)=\gamma(y, x)$, iff $X=\{x, y\}$

(3) Wholeness

$\gamma\left(x_{i}, x_{j}\right) \neq \gamma\left(x_{j}, x_{i}\right)$ almost always, iff $X=\left\{x_{i} \mid i \in I=\right.$ $\{0,1,2, \ldots, m\}, m \geq 2\}$

(4) Approachability

$\gamma\left(x_{0}(k), x_{i}(k)\right)$ decreases along with $\left|x_{0}(k)-x_{i}(k)\right|$ increasing.

Evaluation criteria for port competitiveness include qualitative and quantitative data. The data have to be normalized, and then calculate the grey relational grade $\Gamma_{0 i}$. The seven steps are described as follows:

Step 1. Define the evaluation criteria data matrix. Data matrix $x_{i}(k)$, where, $k$ is the number of criteria, and $i$ is the number of ports.

Step 2. Look for the maximized or minimized objective value as reference series $x_{0}$. For the cost and distance criteria, select the minimum value as the reference series, and for any other criterion, select the maximum value as the reference series.

Step 3. Place other values $x_{i}(k)$ besides $x_{0}$ as comparison series.

Step 4. Calculate $x_{i}^{*}(k)$ by means of normalized treatment among units of the evaluation criteria.

In order to avoid the evaluation indicators violating the comparison feature, this study transfers indicators into normalized variables $x_{i}^{*}(k)$. For example, if they involve values 1 and 1000, then the order difference is 3 . This is over 2 and doesn't meet the requirement. Three conditions are as follows:

(1) Maximum type. The greater, the better.

$$
x_{i}^{*}(k)=\left(x_{i}(k)-\min _{k} x_{i}(k)\right) /\left(\max _{k} x(k)-\min _{k} x_{i}(k)\right)
$$

(2) Minimum type. The smaller, the better.

$$
x_{i}^{*}(k)=\left(\max _{k} x_{i}(k)-x_{i}(k)\right) /\left(\max _{k} x_{i}(k)-\min _{k} x_{i}(k)\right)
$$

(3) Goal-expected type. The smaller gap to the goals, the better.

$$
\begin{aligned}
& x_{i}^{*}(k)=\left(\left|x_{i}(k)-x_{o b}(k)\right|\right) / \max \left\{\max _{k} x_{i}(k)\right. \\
& \left.-x_{o b}(k), x_{o b}(k)-\min _{k} x_{i}(k)\right\}
\end{aligned}
$$

Step 5. Calculate the series difference between the reference and the comparison series.

$$
\Delta_{0 i}(k)=\left|x_{0}(k)-x_{i}(k)\right|
$$

Step 6. Calculate of the comparison series and the grey relational grade $\Gamma_{0 i}$.

$$
\begin{aligned}
& \Delta^{\prime}=\sqrt{\frac{\sum_{k=1}^{n} \Delta_{0 i}^{2}(k)}{n}} \\
& \Gamma_{0 i}=\left(\Delta_{\min }+\Delta_{\max }\right) /\left(\Delta^{\prime}+\Delta_{\max }\right)
\end{aligned}
$$

Where, $\Delta_{\max }=\max _{i} \max _{k} \Delta_{0 i}(k)$,

$$
\Delta_{\max }=\min _{i} \min _{k} \Delta_{0 i}(k)
$$

Step 7. Display the port competitiveness order by grey relational grade $\Gamma_{0 i}$.

When considering the distinguished coefficient, then the grey relational grade $\Gamma_{0 i}$ is as follows:

$$
\Gamma_{0 i}=\left(\Delta_{\min }+\zeta \Delta_{\max }\right) /\left(\Delta^{\prime}+\zeta \Delta_{\max }\right)
$$

The major function of the distinguished coefficient $\zeta$ is compared between background and tested object values. The coefficient $\zeta$ could be adjusted to one's demand. Generally, $\zeta$ is 0.5 . In that case, the value of $\Delta_{\min }$ generally equals zero. Factor $\Delta_{\min }$ can be omitted from formula (8). When considering different importance among indicators, we can merge weights into the grey relational grade formula [formula (9)].

$$
\Delta^{\prime}=\sqrt{\sum_{k=1}^{n} \beta_{k}^{2} \Delta_{0 i}^{2}(k)}
$$

Where $\sum_{k=1}^{n} \beta_{k}=1$

\section{EMPIRICAL STUDY}

The hierarchical structure contains seven levels as shown on APPENDIX A. The alternative level are eight competitive container ports, Keelung, Taichung, Kaohsiung, Kobe, Hong Kong, Shanghai, Pusan, and the port of Singapore. Level 1 is the goal. Level 2 contains internal and external environments. Level 3 contains strengths, weaknesses, opportunities, and threats. Internal environment includes three aspects, including manpower, organizations, and physical facilities. External environment includes politics, society, economy, and finance (Level 4). Level 5 are objectives, including labor quality, operation style, efficiency, location and cargo source, hardware and software, comprehensive plan, as well as external environments that include political stability, social stability, economical stability, financial stability, and productivity. Then, evaluation criteria are shown on Level 6 and Level 7 and drawn up 31 criteria. Shown as APPENDIX A. 
The hierarchy scoring method (HSM) is applied in the competitiveness analysis framework. Its advantages are simplicity of operation, a synthesis of opinions from most experts and decision makers, and quantitative analysis. The major steps of the HSM are as follows:

1. Define research problem.

2. Select member of interviewees.

3. Construct a hierarchical structure and criteria.

4. Propose evaluated ports.

5. Propose questions and undertake questionnaire survey as follows: (1) Interviewee ranks criteria's orders according to their importance; (2) Interviewee score criteria in scale 1-100 on each level. (3) Interviewee score ports' performances under each criterion in scale 1-5 excepting some criteria with statistical data.

6. Calculate weights of criteria.

7. Compute the synthesized performance values via GRA method.

There are 22 valid questionnaire sheets out of approximately one hundred submitted ones. These interviewees include local professionals, officials, carriers, and overseas carriers. The weights of criteria are calculated in accordance with HSM procedure stated in the above. Criteria and weights are shown in APPENDIX A. From the criterion weights shown in APPENDIX A, it is evident that the least important criterion is $0.3 \%$ and the most important one is $10.2 \%$.

The evaluated ports are ranked based on the grey relational grade $\Gamma_{0 i}$ of the GRA method. The ranking orders are illustrated in Table 1, as Singapore, Hong Kong, Kaohsiung, Kobe, Taichung Port, Keelung, Pusan, and Shanghai. Singapore, synthesized performance 0.9744 , is in the first place and it obtains excellent performances in most of the criteria. Hong Kong has the highest annual container handling volume and the second transshipment boxes of container. Its performance is 0.9140 . Other ports performance values are 0.9110 , $0.8980,0.8617,0.8557,0.8505$, and 0.8338 , respectively. If the synthesized performance is divided into three equal intervals, then Singapore resides in the first grade, Hong Kong, Kaohsiung and Kobe in the second grade,
Pusan, Keelung, Taichung Port, and Shanghai in the third grade, as shown in Table 1.

\section{DISCUSSION}

The weights of criteria are not constant, from the least important criterion $0.3 \%$ to the most important one $10.2 \%$. Namely, the less important criterion can be screened. Therefore, criteria are deleted one after another by their weights in this study. When 13 criteria are left, the weight summation is $79.4 \%$ of the total 31 criteria. Keeping on screening after 11 criteria, the ranking order has changed, illustrated on Table 1. According to Pareto Rule, $80 \%$ of total weight is select, i.e. 13 criteria are the critical criteria. These 11 criteria only share 0.735 are not suggested because of their total weight being far under $80 \%$ of the original. But rather because 13 indicators is a critical minimal number of criteria, the action of indicator screening stops.

In addition, the ratio between the effectiveness type of criteria and the efficiency type of criteria is approximately 70 over 30 as shown in Table 1 . This feature is also illustrated in Huang et al. [13]. That paper collects relative researches and concludes that criteria percentage of effectiveness and efficiency between port productivity and port competitiveness are quite different, illustrated in Fig. 2. In order to understand competitiveness development for port planners, this section is to start a prospect analysis of comparing the port competitiveness for three container ports of Taiwan. This will provide guidance for competitiveness and development for the operators of these ports. The criteria are the essential 13 items to improve operational efficiency. Two situation are illustrated as follows:

1. Situation one: Taiwan's political and economic environment keeps worsening in the next five years. The performance values of social, political, and economic stability indicators of $c_{27}, c_{28}, c_{29}, c_{30}$ are downgraded one position to a grade-five scale. Pusan and Shanghai would be economically and politically stable. Therefore, $c_{5}, c_{6}, c_{27}, c_{28}, c_{30}$ and $c_{31}$ are upgraded one grade. Moreover, Shanghai's quantity of port facilities

Table 1. Port competitiveness ranking

\begin{tabular}{llllllllll}
\hline Ports & Keelung & Taichung & Kaohsiung & Hong Kong & Shanghai & Pusan & Kobe & Singapore & Remarks \\
\hline 31 criteria & 0.8557 & 0.8617 & 0.9110 & 0.9140 & 0.8338 & 0.8505 & 0.8980 & 0.9744 & Efficiency: 28.9\% \\
Rank & 6 & 5 & 3 & 2 & 8 & 7 & 4 & 1 & Effectiveness: 71.1\% \\
Grade & III & III & II & II & III & III & II & I & \\
Use 13 criteria & 0.8613 & 0.8657 & 0.9131 & 0.9149 & 0.8383 & 0.8530 & 0.9014 & 0.9773 & Efficiency: 25.7\% \\
(Share 79.4 \%) & 6 & 5 & 3 & 2 & 8 & 7 & 4 & 1 & Effectiveness: 74.3\% \\
Use 11 criteria & 0.8642 & 0.8690 & 0.9171 & 0.9150 & 0.8412 & 0.8548 & 0.9048 & 0.9773 & Efficiency: 27.8\% \\
(Share 73.5\%) & 6 & 5 & 2 & 3 & 8 & 7 & 4 & 1 & Effectiveness: 72.2\% \\
\hline
\end{tabular}


Table 2. The ranking orders of the prospect analysis

\begin{tabular}{cccccccccc}
\hline Situation & Keelung & Taichung & Kaohsiung & Hong Kong & Shanghai & Pusan & Kobe & Singapore & Total weights \\
\hline Original & 6 & 5 & 3 & 2 & 8 & 7 & 4 & 1 & $\Sigma \mathrm{W}=1$ \\
I & 8 & 7 & 6 & 2 & 4 & 5 & 3 & 1 & $\Sigma \mathrm{W}=0.792$ \\
II & 5 & 4 & 3 & 2 & 8 & 7 & 6 & 1 & $\Sigma \mathrm{W}=0.792$ \\
\hline
\end{tabular}

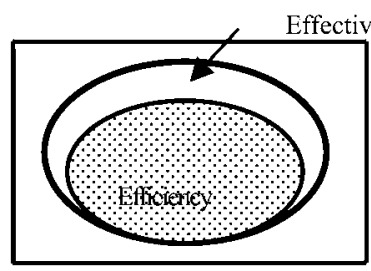

Port productivity

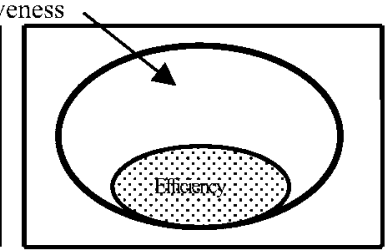

Port competitiveness
Source: [13]
Fig. 2. Criterion percentage of effectiveness and efficiency between port productivity and competitiveness.

keep rising, and so $c_{7}, c_{8}, c_{9}$ are upgraded one grade. The $c_{13}$ import/export cargo volumes are updated to year 2002. The results of the ranking order for the ports are shown in Table 2. The port competitiveness ranking sequence now is Singapore, Hong Kong, Kobe, Shanghai, Pusan, Kaohsiung, Taichung and Keelung. Kaohsiung Port falls behind Pusan and Shanghai.

2. Situation two: Taiwan's three major ports improve in several fields. Indicator $c_{1}$, labor quality, $c_{2}$ custom's effects, $c_{5}$ and $c_{6}$ all are promoted one grade. $c_{27}$ and $c_{30}$ keep developing. $c_{29}$ and $c_{31}$ for political and social economic stability, respectively, are improving to Singapore's level. $c_{13}$ updates to 2002 counts for those ports. The final ranking orders via the GRA for Kaohsiung and Hong Kong become close. The competitiveness of Kaohsiung will improve to the level of Hong Kong. The competitiveness of Keelung and Taichung are also improving, and the ranking of their positions are significantly on the rise (as shown in Table 2).

The DEA is a non-parametric method which computes the relative efficiency of the evaluated object and compares it to the frontier. OCRA is similar to DEA. It uses linear programming approach to establish an analytic model. Game theories include two types, the Cournot model and the Bertrand model. The Stackerlberg model is a dynamic game model. Port competition researches apply game theories to establish a port throughput allocation model. The game theory belongs to the micro model. Some researches adopt the Cobb-Douglas production function with annual income as output, and labor and asset as inputs. Some adopt multiple criteria to measure productivity, such as the productivity of a container base, cranes, wharves, and labor force [5].
This paper uses the GRA to handle the competitiveness of container port's ranking order. We confirmed that those methods are pertinent for this type of research. This research also extends the GRA to sensitivity analysis by screening criteria numbers and by applying these critical criteria to a prospect analysis. In this empirical case, thirteen indicators were used in the prospect analysis. One can simulate several conditions to the analysis through simple processes and sensitive reaction. The critical criteria consist of labor quality, financial stability, political stability, ship mean time in port, productivity, economic stability, loading and discharging ratio, terminal movement capability ratio, operation cost of carriers, port service charge, impact of custom service, inbound/outbound, operational efficiency.

\section{CONCLUSIONS}

This paper focused on the evaluation of ports competitiveness, and has undertaken an empirical study of eight container ports in the East Asian region. Since port sector is a public one. Therefore, it's appropriate to use GRA of multicriteria decision-making methods in the competitiveness analysis of a port. Sensitivity analysis has been taken by using 31 and 13 criteria as critical points in comparison. The results showed no significant difference among them. This result indicates that criteria screening is not sensitive when the number of criteria decreased from 31 to 13 . Moreover, the weight summation of 13 criteria shared 80 percent of the original criteria, and 13 criteria matched the Pareto Rule of threshold of $80 \%$. These 13 criteria were representative of the basic critical minimum number of criteria.

This research has found that evaluation criteria for port competitiveness can be selected in accordance with those with greater weights in the proper order following the Pareto rule. Therefore, we selected the top $75 \%$ to $80 \%$ of the evaluation criteria and deleted the others with lower weights to increase the evaluation effect. The major evaluation criteria include labor quality, financial liberalization, political, social, and economical stability, hinterland productivity, ship mean service-time in port, loading and discharging ratio, terminal movement capability, operation cost of carriers, port service charge, impact of customs service and 
inbound/outbound ratio. Furthermore, port competitiveness evaluation would regard the effectiveness type of criterion as the principle ones, and the efficiency type of criterion as a minor one, and the ratio should be approximately 70/30. This ratio is proven to be appropriate from the statistics shown in the related literatures.

Taiwan's three major ports have to improve their labor quality, operational cost for carriers, service charges of internal factors and so on. The most important factors are political, social, and economic stability. In doing so, the ranking order for Kaohsiung Port is expected to become close to Hong Kong. The competitiveness of Keelung and Taichung can also be improved, and the ranking of their positions are significantly on the rise.

In addition, due to the widely different characteristics of ports, the overall competitiveness comparisons should be on different basis. Further researches are required to classify ports into different categories before being able to effectively start making comparisons among them.

\section{ACKNOWLEDGEMENTS}

The author would like to thank National Science Council of Taiwan, R.O.C. for its support of the research NSC 89-2611-E-019-032. The content of this paper is part of the results from that study.

\section{REFERENCES}

1. Brown, M.G. and Svenson, R.A., "Measuring R\&D Productivity," Res. Technol. Manag., Vol. 31, No. 4, pp. 11-15 (1988).

2. Chang, S., "Production Function, Productivities, and Capacity Utilization of Port of Mobil," Marit. Pol. Manag., Vol. 5, No. 3, pp. 297-305 (1978).

3. Chen, T., "Competitive Advantages of Container Ports," Transport. Plan. J., Vol. 16, No. 3, pp. 449-472 (1997).

4. Chou, C.-C., Chu, C.-W., and Liang, G.-S., "Competitiveness Analysis of Major Ports in Eastern Asia," $J$. Eastern Asia Soc. Transport. Stud., Vol. 5, No. 3, pp. 682-697 (2003).

5. Deng, J., "Introduction to Grey System Theory," J. Grey Sys., Vol. 1, No. 1, pp. 1-24 (1989).

6. Dowd, T.J. and Leschine, T.M., "Container Terminal Productivity: A Perspective," Marit. Pol. Manag., Vol. 17, No. 2, pp. 125-133 (1990).

7. Dutta, B.K. and King, W.R., "A Competitive Scenario Modeling System," Manag. Sci., Vol. 26, No. 3, pp. 261273 (1980).

8. Fielding, G.J., Glauthier, R.E., and Lave, C.A., "Performance Indicators for Transit Management,"
Transportation, Vol. 7, No. 4, pp. 365-379 (1978).

9. Frankel, E.G., Port Planning and Development, Wiley, New York (1987).

10. Huang, M.J., Huang, W.C., Teng, J.Y., and Wu, S.C., "Ports Competitiveness Evaluation-case Study of Eastern Asian Container Ports," Proceedings of Eastern Asia Society for Transportation Studies, Hanoi (2001).

11. Huang, M.J., Huang, W.C., Teng, J.Y., and Wu, S.C., "Competitiveness evaluation for Eastern Asian Container Ports by Using Grey Relational Analysis Method," J. Grey Syst., Vol. 14, No. 3, pp.239-250 (2002).

12. Huang, W.C., Chen, K.L., and Chien, C.W., "Evaluation indices of Port Transportation System," Proceedings of $12^{\text {th }}$ Academic Seminar, Chinese Institute of Transportation pp. 495-510 (1997). (in Chinese)

13. Huang, W.C., Teng, J.Y., Huang, M.J., and Kou, M.S., "Port Competitiveness Evaluation by Fuzzy Multicriteria Grade Classification Model," J. Mar. Sci. Technol., Vol. 11, No. 1, pp. 53-60 (2003).

14. Huang, W.C., Teng, J.Y., Huang, M.J., and Wu, S.C., "Integration of the AHP and SWOT Analysis for Port Competition Evaluation in the Eastern Asian Region," Proceedings of the Fifth International Symposium on the Analytic Hierarchy Process, Kobe, Japan (1999).

15. Institute of Transportation, Asian Pacific International Port Competitiveness Analysis and Trend Judgment, Taipei (2000). (in Chinese)

16. Jayanthi, S., Kocha, B., and Sinha, K.K., "Competitive Analysis of Manufacturing Plant: An Application to the US Processed Food Industry," Europ. J. Operat. Res., Vol. 118, No. 2, pp. 217-234 (1999).

17. Kaohsiung Harbor Bureau, "Taiwan's Major International Ports Competitiveness Analysis and Core Competence Model Structuring Project- Kaohsiung Harbor," Kaohsiung, Taiwan (1999). (in Chinese)

18. Karnani, A., "Strategic Implications of Market Share Attraction Models," Manag. Sci., Vol. 30, No. 5, pp. 536-547 (1985).

19. Kuroda, K. and Yang, Z., "Stackerlberg Equilibrium Analysis of Container Cargo Behavior," J. Eastern Asia Soc. Transport. Stud., Vol. 1, No. 1, pp. 249-261 (1995).

20. Oral, M. and Dominique, C.R., "An Analytical Approach to Competitive Strategy Formulation in Mature Industries," IIE Trans., Vol. 21, No. 3, pp. 271-278 (1989).

21. Oral, M., Cinar, U., and Chabchoub, H., "Linking Industrial Competitiveness and Productivity at the Firm Level," Europ. J. Operat. Res., Vol. 118, No. 2, pp. 271277 (1999).

22. Oral, M., "A Methodology for Competitive- ness Analysis and Strategy Formulation in Glass Industry," Europ. J. Operat. Res., Vol. 68, No. 1, pp. 9-22 (1993).

23. Parkan, C., "Operational Competitiveness Ratings of 
Production Units," Manag. Decis. Econom., Vol. 15, No. 3, pp. 201-221 (1994).

24. Parkan, C. and Wu, M.-L., "Measuring the Performance of Operations of Hong Kong's Manufacturing Industries," Europ. J. Operat. Res., Vol. 118, No. 2, pp. 235258 (1999).

25. Powell, T.C., "Competitive Advantages: Logical and Philosophical Considerations," Strat. Manag. J., Vol. 22, No. 9, pp. 875-888 (2001).

26. Prescott, J.E. and Grant, J.H., "A Manager's Guide for Evaluating Competitive Analysis Techniques," Interfaces, Vol. 18, No. 3, pp. 10-22 (1988).

27. Robinson, D., Measurement of Port Productivity and Container Terminal Design, A Cargo System Report, IIR Publications, London (1999).

28. Roll, Y. and Rachish, A., "Productivity Measurement at the Plant Level," Omega, Vol. 9, No. 1, pp. 37-42 (1981).

29. Sachish, A., "Productivity Functions as a Managerial Tool in Israeli Ports," Marit. Pol. Manag., Vol. 23, No. 4, pp. 341-369 (1996).
30. Talley, W.K., "Performance Indicators and Port Performance Evaluation," Logist. Transport. Rev., Vol. 30, No. 4, pp. 339-352 (1994).

31. Tongzon, J.L., "Determinants of Port Performance and Efficiency," Transp. Res. Part A, Vol. 29A, No. 3, pp. 245-252 (1995).

32. Tongzon, J.L., "Efficiency Measurement of Selected Australian and Other International Ports Using Data Envelopment Analysis," Transp. Res. Part A, Vol. 35A, No. 2, pp. 107-122 (2001).

33. Verhoeff, J.M., "Seaport Competition: Some Fundamental and Political Aspects," Marit. Pol. Manag., Vol. 8, No. 1, pp. 49-60 (1981).

34. Yang, Z., "Analysis of Container Port Policy by Reaction of an Equilibrium Shipping Market," Marit. Pol. Manag., Vol. 26, No. 4, pp. 369-381(1999).

35. Yeo, K.-T. and Song, D.-W., "An Evaluation of Container Ports in China and Korea with the Analytic Hierarchy Process," J. Eastern Asia Soc. Transport. Studies, Vol. 5, No. 3, pp. 726-741 (2003). 
APPENDIX A. Hierarchy structure and criteria's sweights

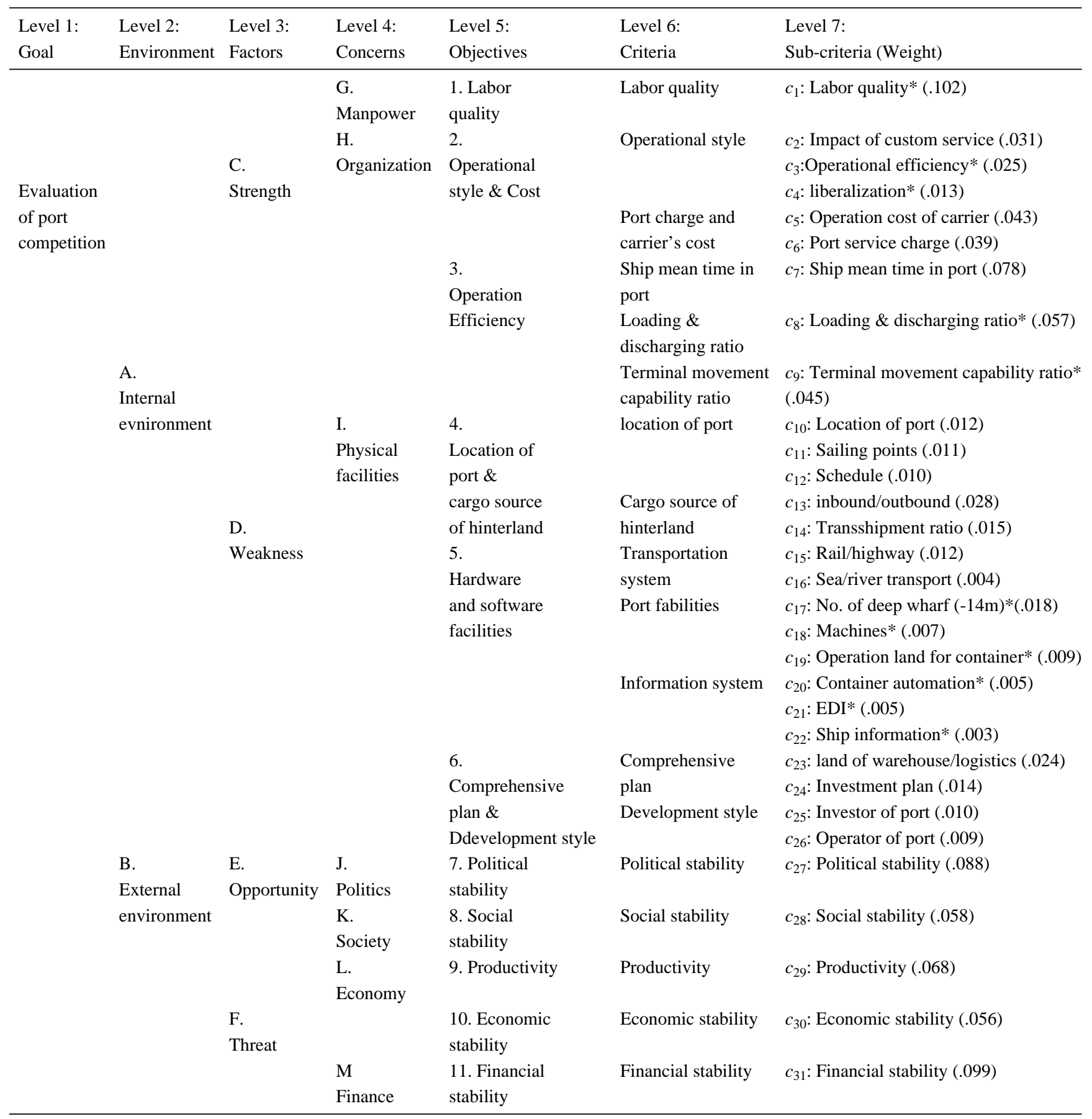

*Efficiency type of criteria.

Source; [14] and arranged by this study. 